\title{
MEMÓRIA-VIAGEM: DA ÍNDIA À INFÂNCIA E AO SERTÃO*
}

\author{
Jerusa Pires Ferreira ${ }^{* *}$
}

RESUMO: O trabalho recupera a evocação de uma viagem feita à Índia há duas décadas. É uma experiência que aproveito para propiciar cruzamentos de memórias em diversas temporalidades. Referências pessoais e culturais se cruzam sob os signos da narração.

Palavras-chave: Memória. Infância. Sertão. Viagem. Educação. Índia.

\section{MEMORY-TRIP: FROM INDIA TO CHILDHOOD AND SERTÃo (NORTHEASTERN BRAZIL)}

ABSTRACT: This work evokes a trip to India two decades ago. I use this experience to supply memory crossing in different times and spaces. Personal and cultural references cross under the signs of narration.

Key words: Memory. Childhood. Sertão. Trip. Education. India.

* A autora recolheu, na Índia e no Nepal, uma grande quantidade de folhetos populares e constituiu um corpus. Está em curso a publicação de um trabalho mais amplo sobre a memória da Índia e sua produção cultural.

Expresso aqui um agradecimento muito especial aos amigos A.P. Joshi e seu filho Arun Joshi, que me abrigaram na maravilhosa cidade de Jaipur, a rosada cidade do Rasjasthan, forte espaço de construção de memória, que merecerá destaque num outro e próximo texto.

** Livre-docente pela Universidade de São Paulo (USP), professora do Programa de Pós-Graduação em Comunicação e Semiótica da Pontifícia Universidade Católica de São Paulo (PUC-SP) e coordenadora do Centro de Estudos da Oralidade (puC-SP). E-mail: jpfer@uol.com.br

Cad. Cedes, Campinas, vol. 26, n. 68, p. 9-20, jan./abr. 2006

Disponível em <http://www.cedes.unicamp.br> 


\section{A viagem}

Q

uando embarquei naquele ônibus, às onze horas da manhã, no Aeroporto Charles de Gaulle, e ouvi o chamado aos passageiros "destination Hoh Chi Min Ville", diante de tantos olhos oblíquos comecei a pensar que estava mesmo no ônibus do mundo. Que tipo de memória poderia eu construir no espaço daquela diferença?

Lembrei-me de minha infância, no sertão e na cidade da Bahia, e como sempre quis viajar. Um dia minha mãe me pegou mentindo para moças atônitas, em frente a um grande navio que avistava no mar, da casa de minha tia, na Península de Itapagipe. Eu contava, aos dez anos, o quanto tinha viajado por todo o mundo e o quanto já conhecia do Oriente. E elas, embasbacadas: tão pequena assim e já viajou tanto?

Tanto tempo depois, esta aventura de viver, que iria se prolongar em crescente intensidade, estava marcada naquele dia por um gosto especial: o de virar tudo pelo avesso para ver como ficava, de conviver com os nossos antípodas, de falar e ouvir para se oferecer e para se abastecer de surpresas e emoções. Estava selada a aventura possível.

Foi tão forte esta sensação de viajar, tendo como destino final a cidade de Hoh Chi Min, que eu depois retomaria em minha evocação o nome deste herói, e veio toda uma memória construída pela mídia sobre o Vietnã, e também seus horrores, seu desastre-vitória e sua força. Procurei naquele momento recompor a aura deste guerrilheiro, depois presidente do Vietnã. Pensei mesmo nele como uma espécie de Fernando Pessoa, com seus heterônimos, só que estes aqui de poesia, guerrilha, sabotagem à dominação e de resistência. E tudo, num grande fluxo de evocação, levava à balsa que nos transportaria para aquilo que era, para mim, o fim do mundo. Nova geografia para novos nomes, novas formas, novos cheiros de prazer e desprazer, novo entendimento de antigas verdades, desentendimento de velhas certezas. Nestas circunstâncias, a memória fica acionada em intensidade e em velocidade. É preciso aprender e jogar muito com novas informações: processá-las.

E passamos do ônibus do mundo para o avião. Alojados num especial (por acaso especial) segundo andar de um Jumbo da Air France, teria como companheiros imediatos pessoas envoltas por uma aura de fraternidade, que não sei bem se existe ou se é uma fantasia precipitada pela imaginação e depois recriada pela lembrança. Mas o fato é que 
estamos ali na gaiola do segundo andar, convivendo em descobertas, eu e os outros, todos juntos numa situação também diferente.

Helen, a moça inglesa que conheci, publicitária, tão pragmática quanto possível, contando os tostôes (e tinha tão mais do que eu) e tentando gerir sua liberdade, como se ainda vivesse no espaço da moralidade vitoriana. A meu lado, um muslim (muçulmano - moslem) vestido com sua roupa típica, um belo conjunto de calça, colete e blusão, impecável na postura e no arranjo, jornalista do principal jornal de Lahore, no Paquistão. Entre goles de vinho Bordeaux e aproveitando as mordidas naquele pão dos anjos, ou seja, aquele que nos era servido no céu, protegia e encobria sua mulher mais que do os véus que ela trazia, transparentes mas evidenciando que ela parecia só ter uma função: a de contemplar. Ela não falava inglês e dela emanava todo um mistério que eu não saberia explicar nem poderia dispor. Quando the falei que ela era simpática e que eu gostaria de dizer-lhe algo, que gostaria de conversar com ela, tive imediatamente sua resposta. Sem consultá-la, ele me afirmou que à sua mulher bastava mesmo que eu gostasse de seu marido, falasse com ele. Só era isso o importante para fazê-la feliz. E o curioso é o jogo aceito pela relação, e isto a fazia feliz (das insídias não sei), que já não se habituara às consultas prévias deste tipo e que ali as regras eram bem claras. Se houvesse revolta, essa deveria passar por outros lugares. Ela ali seria mesmo, e socialmente, a criança protegida, no prato a comida, no banheiro o xixi, acompanhada até a porta do toalete, nas pernas os cobertores sempre postos e bem arrumados. Na melhor das hipóteses, não é assim que se faz para educar crianças abastadas, em nossa civilização ocidental?

Defronte, viajava um eficiente e simpático engenheiro-geólogo de Singapura (Malásia). De repente, a evocação de minha infância: Amok, $o$ louco da Malásia, de Stephan Zweig, que líamos e que as primas mais velhas usavam, mesmo que não tivessem lido, para aterrorizar as menores, naquelas noites frias em que dormíamos na fazenda de minha madrinha, no sertão da Bahia.

Veio daí sua sugestão prudente e eficiente, por parte daquele engenheiro dos futuros caminhos que eu iria pisar no Nepal, destino que tomaria depois da Índia. Procurou roteirizar e medir a minha audácia e eu fui permitindo, tentou traçar junto comigo os meus limites de mulher viajando sozinha, de acalmar o meu desejo heróico e temerário de andar 
desacompanhada por lugares desconhecidos. "Nada de mal no Nepal" - é o que tentava me dizer, não um protetor, mas um intérprete agudo de minhas propostas. A mulher ali é respeitada como uma deusa, me dizia.

De repente, e de quando em quando, um sacerdote muçulmano, lutando por desembaraçar-se do gordo companheiro de banco e manejando as suas saias, punha-se a enrolar melhor os seus turbantes superpostos, estendia seus tapetes no chão e orava voltado para Meca. Não sei como é que ele a conseguia localizar, a partir dali, mas o fato é que conseguia articular uma cidade sagrada alta e ideal que se apresentava a todos nós como a sugestão de um traçado imaginário, sempre que se conseguia captar a inteireza de sua figura.

Até a aeromoça entrou no clima e tentou seguir o rumo de tudo e me descobriu brasileira, a única da América Latina naquele seu barco de surpresas. E eu identifiquei sua origem provençal, sua formação familiar tão semelhante à de uma amiga, pelas linhas do seu rosto, pela postura composta, no relato do seu amor a um brasileiro, com quem vivera e de quem ainda gostava. Azuis seus olhos doces, seu nome Bernadette e, enfim, a amizade que lhe permitiu me convidar para, na volta, me hospedar em seu apartamento, em Paris.

O vôo muito baixo mostrava as cidades, explicava o trajeto. Bucarest, a visão de Santa Sofia e, finalmente, a chegada da primeira escala prevista, o nome que para mim ainda não existia e que de repente se fez ouvir, mais vivo ainda, dias depois nas manchetes dos jornais de todo o mundo, pelas sugestões do terrorismo, pela explosão de uma bomba Karrachi: um mar de luzes, uma cidade que me disseram ter sete milhôes de habitantes, aquele mundo de pessoas ali no Paquistão, que vivia em conflito prolongado com a Índia. Depois, aprenderia tanto mais na Cachemira, segundo o jornalista da terra, que estava conosco e que me apresentava rudimentos de sua língua, o Udur, como mais um dos desafios à minha compreensão, um exercício previsto ao meu novo ritmo de memória. Teria que aprender, em ritmo acelerado, novos nomes, novas designaçóes, novas posturas.

A seqüência seguinte seria Delhi e eu não experimentaria ainda desta vez a emoção de poder chegar a Bankok e finalmente a Hoh Chi Min. Assim que fiquei no meio daquele caminho, na capital da Índia, de cujas festas da Independência eu iria depois participar e até discursar em praça pública. 
Para descer e aí ficar, começavam a pesar também para Helen as tensóes acumuladas, os medos das anunciadas misérias, o perigo que as muitas vacinas que tomamos, antes de chegar, procuravam deter. E ela trazia pílulas para tudo, de alho contra infecção, pastilhas para purificação da água. Meu Deus, foi isso que nos fez ficar, de repente, tão amigas, na fila do lavatório do aviāo! Resolvemos dividir nossos medos, exaltar nossa coragem. Viajar é sempre estar em estado de ousadia, sobretudo a de se desafiar e se contrapor, como disse alguém, carecer de nexos, ter a oportunidade de se encontrar consigo mesmo, numa outra solidão. Topamos seguir juntas até que desse, e assim fomos surpreendidas pelo Aeroporto de Delhi, com sua modernidade, seu tapetes geométricos e que, de repente, me lembraram os do aeroporto de Kopenhagen!

Começamos a ver como era, ao mesmo tempo, verdade e mentira tanta coisa disparatada que nos tinham contado sobre a Índia e como aconteciam coisas com as quais não contávamos. Tudo demorava mais do que o habitual e com muita calma, que, a partir daí, sabíamos seria preciso assumir, até como atitude de vida. Andamos percorrendo as listas de hotéis e procurando ver referências de preços, e pensamos em contratar um táxi. Afinal, já eram duas horas da manhã.

Comecei a ver de perto as dificuldades que têm os indianos (sobretudo os mais humildes, como aqueles empregados do aeroporto) de lidar com papéis. A lista dos hotéis estava amassada, meio rasgada, como deveres amarfanhados de menino sujinho de escola primária. E me lembrei então que fui sempre um pouco assim. Que eu nunca consegui ter nada arrumado e que também amassava as pontas, violava as exatas dobraduras de qualquer coisa, jogava fora e perdia e depois recuperava amassados papéis que me serviam. Lembrei do colégio das freiras Sacramentinas, rigorosas naquele tempo, em seus projetos de ordem e conseqüente punição. Eu sujava tudo, derramava os tinteiros sobre a mesa (naquele tempo eles eram de vidro, apoiados em espaços cavados na madeira das carteiras). Eu emporcalhava tudo em que tocava, ficava de castigo nos intervalos e, depois, fazia xixi nas meias e voltava para casa, como diria o poeta Manuel Bandeira (o poeta brasileiro de mais poderosas artes de evocação), toda mijadinha. Minha mãe me tirou da escola.

Foi a lembrança de tudo isso que me levou a começar, de saída, me identificando com aquela gente indiana. Decidimos então e às tantas horas, por curiosidade e aventura, pegar um ônibus em vez de táxi

Cad. Cedes, Campinas, vol. 26, n. 68, p. 9-20, jan./abr. 2006

Disponível em <http://www.cedes.unicamp.br> 
para começar a seguir de perto o que nos aguardava, sem mistificaçóes ou fantasias.

No escuro as coisas ficam mais difíceis, mesmo já fazendo muito calor, e o ônibus era exatamente como o daqui, em meu passado, o que a gente costumava chamar de "marinete" no Nordeste.

E a Índia começou a ser mesmo um mergulho à infância e também visão antiga do futuro, começo e fim do mundo, a linha que une as mais arcaicas formas de procedimentos, de artefatos e de práticas aos mais avançados projetos de vida social, das engenhocas manuais ao desenvolvimento da eletrônica.

A velha "marinete" partiu depois de muito cheia, antigos estribos altos, uma viagem de sacolejos até o centro e os hotéis. Até aí não tínhamos decidido para onde ir e, finalmente, desembaraçadas para catar o que era nosso, vivemos a aventura de embarcar numa coisa que na noite parecia um pequeno monstrinho, um pequeno morcego, um bicho aturdidor e que, durante o dia, parecia, na hora do rush, as vespas de um vespeiro em fúria. Não foi à toa que se deu esse nome às pequenas motos: Vespa. Assim, contratamos com o motorista desta coisa que ali se chama de "Scoorter" e que, aos giros sobre o próprio eixo, nos conduziu não aos hotéis que tínhamos pedido no aeroporto e que Helen já detectara nos seus livros sobre a Índia, mas a uma pensão. Aliás, ela tinha um que informava tudo sobre tudo. Todo estrangeiro que encontrei trazia este livro. India, se chamava, e dava tanta leitura sobre os preços, os lugares, onde andar, comer e dormir, que nunca tive curiosidade em pegar. Limitei-me a ouvir, mas o método rigoroso de minha amiga fazia consultá-lo o tempo todo, esquecendo mesmo a vida, perdendo detalhes e a contemplação do que se passava ao redor.

Foi assim que a vida desfez aquilo que o livro indicava e o destino, a sorte, se encarregava do resto. Fomos parar num Hotel Citizen, nos limites entre a velha e a nova Delhi, paragem que eu iria incorporar para sempre no meu roteiro afetivo, no meu lastro das memórias fundamentais.

Sentamos no jardim (gostosas cadeiras de jardim), mas, se lá fora tudo nos parecia terrível, aqui dentro era tudo inusitado. De passagem pelos passeios, vimos camas e famílias inteiras com todas as suas tralhas dormindo nas calçadas; vimos tudo o que um cidadão tem e não tem, exposto à quente noite de Delhi. Nos mesmos lugares, depois, tive a oportunidade de ver tanta gente depositando os seus dejetos na calçada, 
onde também viria muita gente se lavando nas águas das torneiras públicas e secando suas roupas alvas ou coloridas, calçadas nas quais encontramos brancas vacas nelores, comendo o que podiam. E eu, nascida no sertão, criada nos domínios do zebu, mais do que maravilhada, me incluía naquela ambiência.

Dentro do hotelzinho, os empregados dormiam pelo saguão, enrolados em colchas e, depois, carregando seus colchonetes quando dava a manhã, se levantavam. Era mesmo a Índia que estava se oferecendo aos nossos olhos e ao nosso espanto e afeto!... Eu olhava para Helen e perguntava como ela estava se sentindo, e ela, muito direta, respondia: muito bem.

De manhãzinha, comecei a ter muita saudade de meu pai e apareceu um medo de ter que ficar ali para sempre. Muitos pássaros cantando, muitos corvos mais uns esquilinhos listrados, tão bonitos e ariscos. Resolvemos andar para o parque Pali, que ficava no centro, junto a Connaught Place, e dali avançar em descobertas. Fomos andando e observando no parque as pessoas nos olhando, com olhos de penetração e de profunda eternidade. Fomos ficar perto de tantos iogues, de anciãos que faziam seus exercícios de respiração, esperando o despertar da cidade. Fomos tendo sede e nos tinham dito tanta coisa, que na Índia não se pode beber água, e às vezes os americanos, os ingleses, os europeus levam tudo muito a sério demais; e isto foi se transformando em inquietação e o sol já esquentava muito. Deu sede mesmo. Foi então que descobrimos, no mercado central, que a Bahia dá mesmo régua e compasso para viver tudo isso. E me senti como no antigo Mercado Modelo de Salvador, no cantinho das batidas e das ostras. Este lugar internamente parecia muito sujo, mas a sede era grande e experimentamos pedir chá. O chá era fervido numa grande panela junto com o leite e, depois, tudo sacolejava num coador enorme.

Nas mesas, homens muito pobres e vestidos de algodão, nem sempre alvo, estavam indo para suas lidas diárias. Tomamos o chá, comemos algumas espécies de pão e uma especialidade que era um pão chato (semelhante aos chapatis), um molho de grão de bico, cebola e apimentados. Trocamos olhares com algumas pessoas, fomos bem servidos, comemos com gana e pedimos outro chá. E eu sempre perguntando a Helen, como se ela fosse um termômetro ocidental: - Que tal? E ela: - me sinto muito bem. E eu, concordando. 
Foi daí que resolvemos voltar, entrar no hotel e, então, descobrimos que as camas que tínhamos visto na calçada à noite já não estavam mais lá. É como se tivesse sido montado um grande circo noturno e os acrobatas, durante o dia, tivessem a sutileza e a perfeição de esconder seus aparelhos, retirá-los da cena e guardá-los. Foi aí que começamos a perceber que a gente podia estar bem no centro de toda esta engrenagem que é a Índia, no centro de toda descoberta do outro - que é a vida.

Por isso, foi se dissolvendo todo o medo ao desconhecido, foi crescendo o gosto de estar ali entre as pessoas. Começou a existir, com a regularidade do indispensável, o passeio pelas arcadas de Connaught Place, espécie de mostruário exemplar da vida na Índia, o apelo dos empórios, a orgia visual e sensorial dos objetos, milhares deles, de todas as formas, de todas as cores, e mais os cheiros e também os vendedores e mendigos, com suas técnicas muito especiais de se aproximarem. Sob o belo conjunto de arcadas, as folhas para mastigar, os molhos rosados que tingiam a língua das pessoas, naquele mascar contínuo, e que resultava num cuspe vermelho, em princípio assustador e depois já natural. Foi aí que aprendi a arte de enxotar mendigos, que comecei a aprender a lidar com meu sentimentalismo humanitarista. Pude olhar de frente, e sem lágrimas, as coisas que nossa piedade não suporta. E o pior era dizer não às crianças e rejeitá-las, magras e suplicantes. Mas era assim ou partir.

Chegara o 14 de agosto, véspera das comemoraçōes da Independência da India, e este fato estava em toda parte. Nos retratos de Indira, pregados nos postes, nas bandeirolas cor de telha e verde, as cores nacionais, na esperança que desperta nas pessoas o lidar com a idéia de independência, mesmo que se acredite, como é o caso, em outras vidas; ser independente é como se assumir a si próprio todos os seus impasses e parasitas. É não precisar humilhar-se tanto. Aliás, uma coisa que nunca consegui suportar ver foi a humilhação. Fico tão aflita ao observar certas situaçōes. Consigo ver de perto a morte, descartar o rosto da fome e seguir andando, só não consigo é ver gente humilhando gente. Através de palavras, gestos, atos diversos e nas dobras de atitudes de pessoas aparentemente corretas, e nas entrelinhas de suas ações diárias. Fui observando práticas humilhantes, mesmo quando não intencionais, que me fizeram dona de um ódio surdo. Foi assim que tive de brigar num restaurante em Delhi com uma moça estrangeira, no Nirula's, três dias depois de minha chegada, porque ela, não respeitando a lentidão local, 
xingava de idiotas os moços que a serviam. Mandei parar, não suportei. Adiante, irritei-me com uma outra, a ponto de não a poder mais olhar, por causa do tipo de barganha que fazia sempre com os outros "legítimos inferiores".

$\mathrm{Na}$ Índia, a barganha é uma prática usada por todos os vendedores, como no Oriente em geral, mas, como sabemos, tudo tem seus códigos, comporta suas espertezas, suas pequenas safadezas. Tudo tem, porém, os seus limites, a lógica onde as coisas se encaixam. Mas a quebra destes limites por ela foi tão forte que eu e o dono do bazar, onde ela tentava, sem a menor sensibilidade, deixar o seu dinheiro, nos olhamos e, naquele olhar, entendemos tudo sobre as práticas da ofensa e até onde era possível ser esperto e ético, e até onde a dominação do visitante de fora aos nossos pobres países, dependentes desses dólares, eram um vergonhoso acinte. $\mathrm{O}$ homem lhe disse que lhe entregava então, de presente, as roupas que ela decidira pagar ao seu modo, já que ela precisava tanto dessas migalhas. Ela não entendeu e saiu muito contente, sobraçando os pacotes. Tive náuseas e voltei para casa. Procurei não mais encontrá-la. Consegui ver ali o desprezo que se tem pela gente do sertão, pelos nordestinos migrantes nos grandes centros brasileiros.

Esses eram pequenos, mas intensos fatos que me faziam identificar com a Índia, que me faziam entender que eu não sou apenas brasileira, que vive e adora São Paulo, nordestina e baiana, mas alguém sensível à diferença e atenta às formas de discriminação.

Parece haver mesmo um patamar antigo que conduzia certas vivências, trilhos por onde correriam nossas memórias, caminhos que me ofertavam parâmetros para esta Travessia.

Em algum outro momento, devo acrescentar tantos episódios marcantes, como o atravessar de um trecho dos Himalaias a cavalo, na rota dos tropeiros, cantando versos de Elomar, o arquiteto das sagas do sertão. Ou a vivência de casa-barco em Shrinagar, nas nascentes do Ganges, onde o dia se oferecia ao som dos remos das canoas (shikaras) e, como nos textos do francês Pierre Loti (que lera adolescente), se ouvia a chamada do muezin para a oração do dia. Bem mais tarde, em São Paulo, acordei ouvindo aquele canto e, assustada, busquei de onde vinha, percebendo de súbito que o rádio estava ligado e era um programa na rádio nordestina, acordando os operários para o trabalho com a cantoria. Fortes memórias. 


\section{A circunstância}

Foi em julho/agosto de 1986 que fui à Índia, como membro do grupo de Sociologia da Arte, ${ }^{1}$ para apresentar um trabalho no Congresso Mundial de Sociologia, realizado em Nova Delhi. Nosso grupo de trabalho era composto por pessoas atuando em diferentes áreas e tendo em comum a preocupação pela arte, a passagem por questóes a merecerem o enfoque arte e sociedade. Como o tema geral do Congresso era mudança social, achei oportuno levar um trabalho sobre a literatura de folhetos no Brasil, sob a chamada Cultura popular: tradição e mudança. O sumário que enviei fala de uma literatura popular e de sua iconografia, ainda produzida no Brasil, conhecida como "literatura de Cordel", que se compóe de folhetos artesanais, provenientes do Nordeste e depois livrinhos industriais produzidos em São Paulo, basicamente. Tento aí discutir conceitos de folclore e de cultura popular e, seguindo o processo mais amplo, que envolve textos e para-textos (orais e visuais), vou colocando em xeque a consagrada idéia de uma "memória despótica", como responsável por todas as sequiências da criação popular. Procuro mostrar que a indústria editorial, o texto impresso, tem sido suporte muito sólido para a manutenção de oralidades, para a recriação sucessiva, ditando a permanência de temas e abrindo mais possibilidades para a interferência do artista popular sobre a malha do repertório coletivo.

Procurei trazer questões como a relação entre a produção popular e as sociedades arcaicas, sob o impacto de uma repentina e profunda transformação (migração e modernização).

Passei, portanto, doze dias em Nova Delhi, hospedada e localizada nos limites de um bairro popular, Cole Market, procurando viver, ao máximo, o ambiente das cidades, a Velha e Nova Délhi, que são contíguas, mas deslumbrada sobretudo com a primeira, onde desenvolvi observação sobre a literatura de folhetos populares na Índia. Meu propósito era o de adaptar-me às condiçōes de vida, ao modo de ser das pessoas, embora assustada pelos graves problemas sociais da Índia, tão intensos e bastante diferentes dos nossos. Pude assim perambular por feiras e mercados, templos, mesquitas, seus arredores, para entender aquele mundo, aparentemente tão estranho e finalmente tão familiar. Houve quem dissesse que eu estava buscando ali o Nordeste brasileiro, mas eu, de fato, o estava encontrando, em muitos passos, como encontro sempre o sertão de Feira de Santana, sua memória que refaço e reconstruo por onde ando, mundo afora. 
Não seria preciso procurar muito nem ter um pensamento original para saber que a Índia é um país de tradição rural arcaica, em sua maior parte, que vive o conflito de uma modernização rápida e caótica. A persistente oralidade e a força de um substrato mítico se transmitem na incontável riqueza de uma literatura popular oral e escrita, povoada de crenças complexas, que se vão transmitindo ao longo dos tempos.

É preciso aqui abrir um parêntese para mostrar o outro lado e não passar a impressão de que é esta a imagem do país. Fiquei muito impressionada com o movimento editorial, a qualidade dos trabalhos e publicaçôes indianas. Várias editoras de excelente qualidade estiveram representadas na mostra que se organizou para o Congresso. Além da publicação de autores estrangeiros, há uma produção indiana de boa qualidade, seja em inglês ou em hindi (praticamente o idioma oficial da India), num complexo mosaico de línguas, de crenças de culturas ancestrais. Pude observar o grande interesse de editoras, no sentido de novas produções. É preciso não esquecer a imensa população do país, a crescente escolaridade, o aumento progressivo do número de leitores, sua inserção no contexto asiático, com mercados emergentes e numerosos.

\section{A Índia-laboratório}

Fui participar de um Congresso, cujo tema central era transformação social e modernização, levei um trabalho que tratava das passagens e dos suportes, da oralidade tradicional em direção à modernização e à indústria editorial e, de repente, me encontrei num imenso laboratório de observação. Neste misterioso e aturdidor país, encontrei, para além da grande tradição oral, do adorno dos grãos dispostos cromaticamente nos tabuleiros, oferecendo insuspeitadas geometrias, a imensidão dos cartazes de cinema, uma televisão muito desenvolvida, uma vida moderna em processo. $\mathrm{O}$ cheiro ativo e o paladar intenso revertem nossos padróes e nos fazem aproximar melhor de antigos sabores de uma fertilidade inesgotável; mas há também futuro embutido em tudo isto, aproximações e divergências que obrigam a uma contínua interpretação.

Aconteceu então que terminei, na sessão do meu Comitê, apresentando a comunicação que eu tinha levado do Brasil, fazendo circular os nossos folhetos, para ilustrar as situações de que estava tratando e aproveitando para também apresentar os materiais que já tinha reco-

Cad. Cedes, Campinas, vol. 26, n. 68, p. 9-20, jan./abr. 2006

Disponível em <http://www.cedes.unicamp.br> 
Memória-Viagem: da Índia à Infância e ao Sertão

lhido em Delhi, tentando aproximá-los do nosso conjunto de literatura popular, refletindo e costurando conexões, apontando enfim para um fecundo filáo a ser explorado. Culturas nordestina e indiana (sem esquecer o sistema de castas), a mesma paciência e obstinação, um grande e permanente desafio.

Recebido em setembro de 2005 e aprovado em março de 2006.

Nota

1. O comitê RC37 da I.S.A., cujo presidente é Iván Vitanyi, diretor do Instituto de Cultura de Budapeste.

\section{Referência bibliográfica}

FERREIRA, J.P. Folhetos populares: do Brasil à Índia. Cadernos de Jornalismo e Editoração, Departamento de Jornalismo e Editoração da ECA/ USP, São Paulo, n. 21, jun. 1988. 